\title{
Effects of Prophylactic Continuous Infusion of Phenylephrine on Reducing the Mass of Local Anesthetic in Patients Undergoing Spinal Anesthesia for Cesarean Section
}

\author{
Vinícius Pereira de Souza, TSA ${ }^{1}$, José Luiz Gomes do Amaral, TSA 2 ${ }^{2}$ Maria Ângela Tardelli, TSA ${ }^{3}$, \\ Américo Massafuni Yamashita, TSA 4
}

\begin{abstract}
Summary: Souza VP, Amaral JLG, Tardelli MA, Yamashita AM - Effects of Prophylactic Continuous Infusion of Phenylephrine on Reducing the Mass of Local Anesthetic in Patients Undergoing Spinal Anesthesia for Cesarean Section.

Background and objectives: Reducing the mass of local anesthetic minimizes the effects of hypotension after spinal anesthesia for cesarean section and the incidence of maternal adverse events preserving fetal well-being, but it may result in insufficient anesthesia. Hypotension associated with greater masses of subarachnoid anesthesia can be controlled by prophylactic continuous infusion of phenylephrine. The effects of prophylactic continuous infusion of phenylephrine on pressure control on maternal and fetus results in cesarean sections with different doses of hyperbaric bupivacaine in spinal anesthesia.
\end{abstract}

Methods: A non-randomized prospective study of 60 gravidas at term scheduled for elective cesarean sections was undertaken. Patients were allocated into two groups depending on hyperbaric bupivacaine dose administered for spinal anesthesia, 12 or $8 \mathrm{mg}$, along with $5 \mu \mathrm{g}$ of sufentanil and $100 \mu \mathrm{g}$ of morphine. Patients were hydrated with $10 \mathrm{~mL}^{\mathrm{kg}} \mathrm{kg}^{-1}$ of Ringer's lactate before the anesthesia. Shortly after, continuous infusion of 100 $\mu \mathrm{g} \cdot \mathrm{min}^{-1}$ of phenylephrine was initiated to maintain blood pressure at baseline levels. The following parameters were evaluated: level of anesthetic blockade, consumption of vasopressors, incidence of maternal events, and conditions of the newborn.

Results: Maternal data was similar in both groups regarding the level of anesthetic blockade, phenylephrine consumption along time, incidence of hypotension, hypertension, bradycardia, nausea, vomiting, dyspnea, pain, and tremors. Conceptual data showed similarities between both groups regarding blood gases and umbilical vein lactate levels. The $\mathrm{pH}$ of all newborns was > 7.2.

Conclusions: On maintaining the blood pressure with prophylactic continuous infusion of phenylephrine the incidence of maternal adverse events and conditions of birth do not differ whether spinal anesthesia is performed with $12 \mathrm{mg}$ or $8 \mathrm{mg}$ of hyperbaric bupivacaine.

Keywords: Phenylephrine; Anesthesia, Obstetrical; Cesarean Section; Hypotension; Bupivacaine.

[Rev Bras Anestesiol 2011;61(4): 409-424] @Elsevier Editora Ltda.

\section{INTRODUCTION}

Spinal anesthesia is the technique of choice commonly used for cesarean section worldwide ${ }^{1-4}$. However, hypotension remains the main complication related with this technique ${ }^{5-7}$, associated with several maternal (nausea, vomiting, dyspnea, and discomfort) and fetal adverse events (acidosis and fetal suffering, neurologic injuries, and death) ${ }^{8-9}$.

Received from Hospital Mater Dei, Belo Horizonte, MG, Brazil.

1. Intensive Care Specialist - AMIB; Coordinator of the Serviço de Anestesiologia do Hospital Mater Dei

2. Professor of the Disciplina de Anestesiologia, Dor e Terapia Intensiva of Escola Paulista de Medicina of Universidade Federal Estadual Paulista, EPM-UNIFESP

3. Associate Professor of the Disciplina de Anestesiologia, Dor e Terapia Intensiva of EPMUNIFESP

4. Assistance Professor of the Disciplina de Anestesiologia, Dor e Terapia Intensiva of EPMUNIFESP

Submitted on August 12, 2010.

Approved on December 28, 2010.

Correspondence to:

Dr. Vinícius Pereira de Souza

Rua Araguari, 1331/1401

Santo Agostinho

30190111 - Belo Horizonte, MG, Brazil

E-mail: vinicius.ps@terra.com.br
Several strategies have been used to prevent spinal anesthesia-related hypotension, and among them we highlight the reduction of the mass of local anesthetic and prophylactic continuous infusion of phenylephrine. Addition of liposoluble opioids to spinal anesthesia allowed the reduction of the mass of local anesthetic administered ${ }^{10}$, incidence, severity, and duration of hypotension, consumption of vasopressors, and duration of motor blockade ${ }^{11-16}$. Infusion of phenylephrine has proven to be safe and effective, and it does not have the risk of insufficient anesthetic blockade secondary to reduction in the mass of local anesthetic ${ }^{17-19}$.

The objective of the present study was to comparatively evaluate the effects of prophylactic continuous infusion of phenylephrine on maternal and fetal results of different masses of local anesthetic usually administered in spinal anesthesia for elective cesarean section.

\section{METHODS}

After approval by the Ethics Councils of Hospital Mater Dei in Belo Horizonte/MG, and UNIFESP in São Paulo/SP, and patients signing of informed consent, a prospective non- 
randomized clinical assay was performed with 60 gravidas at term (gestation with more than 37 weeks), physical status I and II according to the American Society of Anesthesiologists (ASA), scheduled for elective cesarean sections.

Exclusion criteria were as follows: obesity with body mass index greater than $30 \mathrm{~kg} \cdot \mathrm{m}^{-2}$; history of preeclampsia and/or prior hypertension; presence of cardiac or cerebrovascular diseases; rupture of the amniotic sac; presence of signs of labor onset; and situations involving contraindications for subarachnoid anesthesia.

Patients were allocated into two groups, $\mathrm{G}_{12}$ and $\mathrm{G}_{8}$, depending on the dose of hyperbaric bupivacaine administered.

Monitoring consisted of cardioscopy, pulse oximetry, and non-invasive blood pressure. An 18G catheter was used for venipuncture. A vesical catheter was used according to the surgical team's criterion.

Ringer's lactate $10 \mathrm{~mL} . \mathrm{kg}^{-1} 10$ to 15 minutes before anesthesia and a total volume of $1,000 \mathrm{~mL}$ until delivery was used for volemic expansion.

Patients were on the sitting position for spinal anesthesia; the space between the second and third lumbar vertebrae was punctured with a pencil tip 27G needle. After puncture, patients were placed in dorsal decubitus with the uterus deviated to the left by placing a wedge below the right hip.

In $\mathrm{G}_{12}$ group, $12 \mathrm{mg}$ of hyperbaric bupivacaine were administered, while in $\mathrm{G}_{8}$ group, $8 \mathrm{mg}$ were administered. In both groups, $5 \mu \mathrm{g}$ of sufentanil and $100 \mu \mathrm{g}$ of morphine were added to the anesthetic solution, which was injected at a rate of $1 \mathrm{~mL}$ every 10 seconds.

Blood pressure was obtained through the oscillometric method, with the cuff of the device on the left arm. The baseline blood pressure was obtained with the patient in dorsal decubitus, without the wedge under her right hip, after she was admitted to the operating room. After neuraxial block, blood pressure was automatically measured every 3 minutes until delivery.

A syringe pump was used for continuous infusion of phenylephrine immediately after spinal anesthesia. Initially, the rate of infusion of phenylephrine was adjusted to $100 \mu \mathrm{g} \cdot \mathrm{min}^{-1}$, and followed by adjustments to maintain blood pressure at baseline levels. The vasopressor infusion was stopped after fetal extraction, immediately after clamping the umbilical cord.

In case of an abrupt fall in systolic blood pressure by more than $10 \%$ of baseline levels, a bolus of $50 \mu \mathrm{g}$ phenylephrine was administered. Hypotension was defined as a fall greater than $20 \%$ in baseline levels.

On the other hand, hypertension was defined as an increase in systolic blood pressure greater than $20 \%$ in baseline levels. In the presence of hypertension, phenylephrine infusion was stopped, to be reinitiated immediately after blood pressure returned to baseline levels.

Bradycardia was defined as a reduction in heart rate below $50 \mathrm{bpm}$. Whenever bradycardia was accompanied by normal blood pressure and/or hypertension, the infusion of phenylephrine was stopped. If bradycardia was accompanied by hypotension, $1.0 \mathrm{mg}$ of intravenous atropine was administered.
In case of pain and discomfort any time during the surgery an intravenous bolus of $10 \mu \mathrm{g}$ of sufentanil associated with $0.2 \mathrm{mg} \cdot \mathrm{kg}^{-1}$ of ketamine was administered.

Immediately after delivery, double clamping of a segment of 10 to $15 \mathrm{~cm}$ of the umbilical cord was performed to collect blood samples from the umbilical vein and artery in a heparincontaining syringe for arterial blood gases and lactate levels. Samples were analyzed up to 60 minutes after being collected.

The anesthetic process predicted levels of sensorial blockade to pinprick in both middle axillary lines 5 to 10 minutes after subarachnoid anesthesia.

Time intervals recorded during anesthesia were as follows: time between end of subarachnoid anesthesia and delivery in minutes; time between uterotomy and delivery in seconds; and time between end of subarachnoid anesthesia and cesarean section in minutes.

The total mass of vasopressor administered, number of hypotensive, hypertensive, and bradycardia episodes; need of atropine; maternal adverse events, such as nausea, vomiting, dyspnea, pain, discomfort, and tremors; and the need of anesthetic complementation until the end of the cesarean section were recorded.

In newborns, the following parameters were analyzed: weight; Apgar index in the first and fifth minutes; and blood gases and lactate levels in umbilical artery and vein.

The Student $t$ test was used in the statistical analysis of continuous numerical variables investigating group homogeneity regarding age, gestational age, weight, initial systolic blood pressure and heart rate, and volume and total mass of vasopressors administered, as well as arterial blood gases and lactate levels in umbilical vessels. Times between anesthesia and delivery and uterotomy and delivery were evaluated by the Mann-Whitney test. A level of $0.05 \%$ was considered significant.

The tendency Chi-square test was used to analyze the intergroup differences in sensorial blockade level. The incidence of maternal adverse events and the need of atropine were analyzed by the Fisher and Chi-square tests.

Excel 97-2003 and SPSS 16.0 were the statistical software used.

Considering a level of significance of $5 \%$, power of $80 \%$, and the primary objective of blood pressure control by the occurrence of nausea and vomiting, it was calculated a sample size of 23 patients per group. Thirty patients in each group were investigated, as data collection was made before calculating the size of the sample.

\section{RESULTS}

The main indications for cesarean sections are shown in Table I. Regarding physical status, it was observed that, in groups $\mathrm{G}_{12}$ and $\mathrm{G}_{8}, 73.3 \%$ and $86.7 \%$ of patients were ASA I, and $22.7 \%$ and $13.3 \%$ were ASA II, respectively.

Both groups were homogeneously regarding patient characteristics (Table II). 
A difference between groups regarding sensorial blockade level 5 and 10 minutes after subarachnoid administration (Figures 1 and 2) was not observed. In both groups sensorial blockade 5 and 10 minutes after the administration of local anesthetic was at $\mathrm{T}_{6}$ and $\mathrm{T}_{4}$, respectively.

Mean anesthesia-delivery times was 23.3 minutes in $G_{12}$, and 18.6 minutes in $\mathrm{G}_{8}$ (Table III) with a significant difference between both groups ( $p=0.0009)$ (Figure 3$)$. Uterotomydelivery time did not show a significant difference between both groups $(p=0.695)$, with a mean of 75.0 seconds in $\mathrm{G}_{12}$, and 73.9 seconds in $\mathrm{G}_{8}$. The mean total duration of the

Table I - Indications for Cesarean Section

\begin{tabular}{lll} 
& $\mathrm{G}_{12}(\mathrm{n})$ & $\mathrm{G}_{8}(\mathrm{n})$ \\
\hline Prior cesarean section & 13 & 15 \\
Cephalopelvic disproportion & 11 & 9 \\
Maternal request & 4 & 2 \\
Others* & 2 & 4 \\
\hline
\end{tabular}

Results presented as number of patients.

*Others: Uterine myomatosis, oligohydramnios, fetal macrosomia.

Table II - Patient Characteristics

\begin{tabular}{llll}
\hline & $\mathrm{G}_{12}$ & $\mathrm{G}_{8}$ & $\mathrm{p}$ \\
\hline Age (years) & $31 \pm 6.2(16-43)$ & $31.1 \pm 5.8(23-43)$ & 0.931 \\
Weight $(\mathrm{kg})$ & $73.3 \pm 10(60-95)$ & $74.5 \pm 11.8(54-104)$ & 0.672 \\
Height (cm) & $161.1 \pm 20(160-176)$ & $163 \pm 5.1(153-171)$ & 0.628 \\
Gestational age (weeks) & $38.6 \pm 0.9$ & $38.3 \pm 0.7$ & 0.154 \\
Baseline blood pressure (mmHg) & $122.3 \pm 10.3(105-42)$ & $121.7 \pm 10.6(100-141)$ & 0.825 \\
Baseline heart rate (bpm) & $87.3 \pm 12.3(64-108)$ & $87.9 \pm 13.9(60-115)$ & 0.875 \\
\hline
\end{tabular}

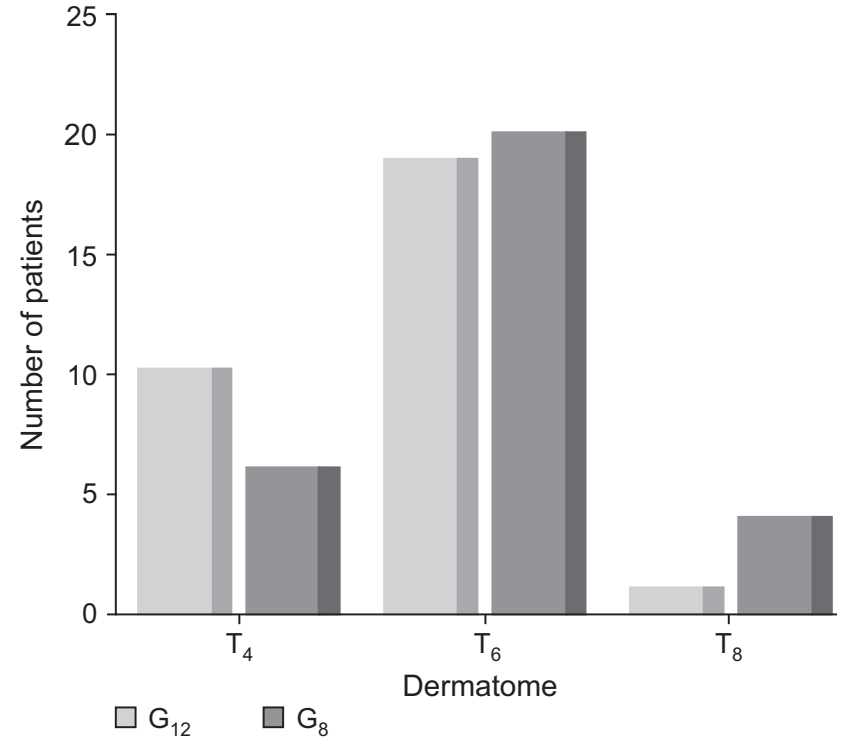

Figure 1 - Sensorial Level 5 Minutes After Subarachnoid Injection in $\mathrm{G}_{12}$ e $\mathrm{G}_{8}$.

$\mathrm{G}_{12}: 12 \mathrm{mg}$ group; $\mathrm{G}_{8}: 8 \mathrm{mg}$ group.

Results presented as mean \pm standard deviation and (minimum - maximum).

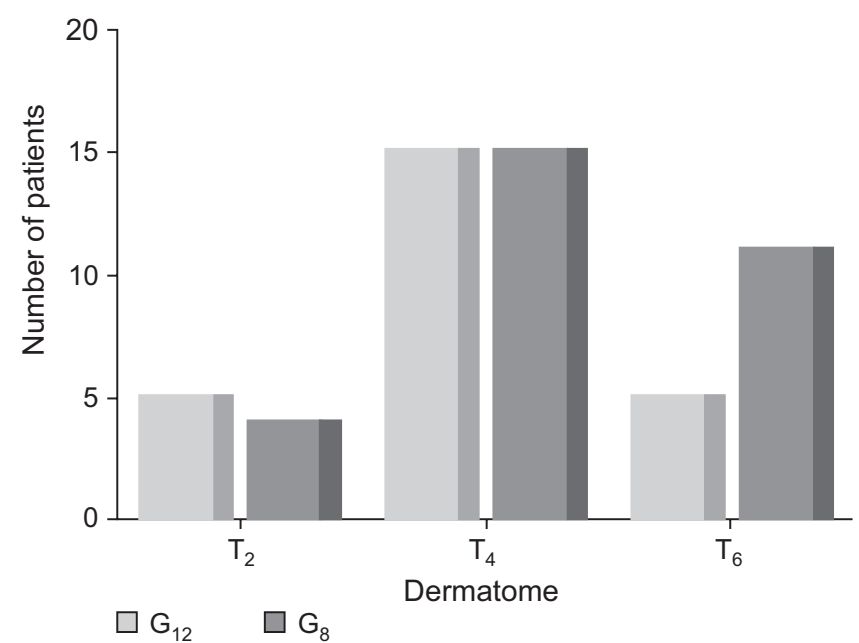

Figure 2 - Sensorial Blockade 10 Minutes After the Subarachnoid Injection in $\mathrm{G}_{12}$ e $\mathrm{G}_{8}$.

$\mathrm{G}_{12}: 12 \mathrm{mg}$ group; $\mathrm{G}_{8}: 8 \mathrm{mg}$ group.
Evolution of Mean Systolic Blood Pressure $(\mathrm{mmHg})$ and Heart Rate (bpm) along Time ( $\mathrm{min})$ in $\mathrm{G}_{12}$ and $\mathrm{G}_{8}$

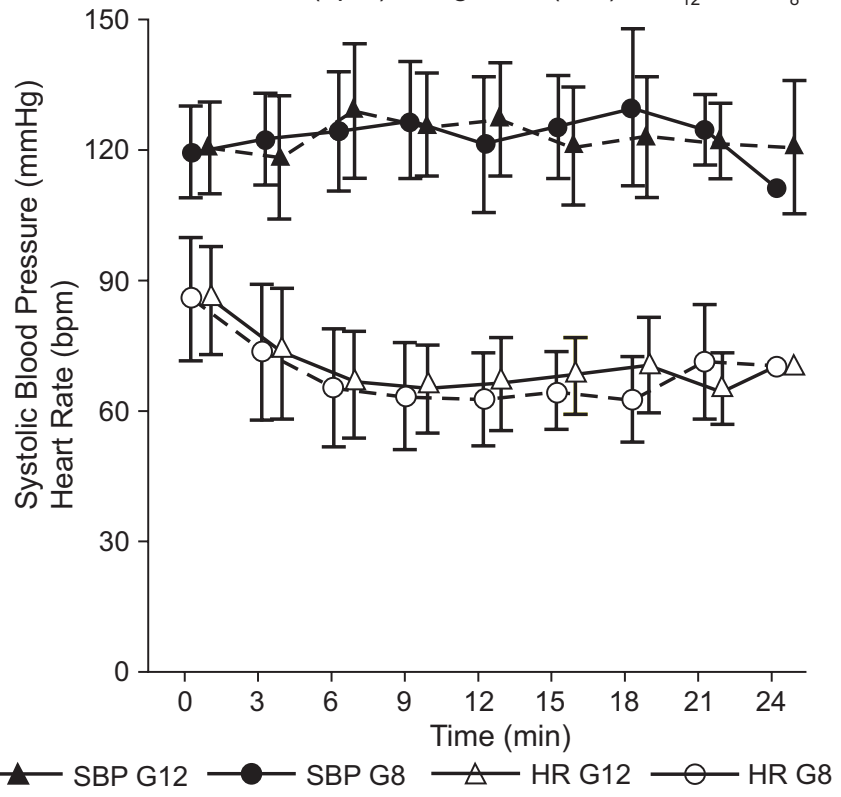

Figure 3 - Evolution of Mean Systolic Blood Pressure $(\mathrm{mmHg})$ and Heart Rate (bpm) along Time ( $\mathrm{min})$ in $\mathrm{G}_{12}$ and $\mathrm{G}_{8}$.

SBP: Systolic blood pressure; HR: heart rate. 
procedure, measured by the anesthesia-end of surgery time was 72.44 and 67.33 minutes in $\mathrm{G}_{12}$ and $\mathrm{G}_{8}$, respectively, without a significant difference between groups $(p=0.171)$ (Table III).

The total mass of phenylephrine administered was significantly different $\left(p=0.0023\right.$ ) between $\mathrm{G}_{12}$ (mean of $1,024.3 \mu \mathrm{g}$ ) and $\mathrm{G}_{8}$ (mean of $794.2 \mu \mathrm{g}$ ). Comparing the relationship between the total mass of phenylephrine administered to the anesthesiadelivery time (phenylephrine infusion time), differences between groups were not observed $(p=0.9753)$. Differences between both groups regarding the incidence of hypotension and hypertension were not observed. The incidence of bradycardia was similar in both groups, without the need of atropine (Table IV).

The greatest and lowest level of systolic blood pressure and heart rate recorded did not differ between groups (Table V). Differences in the evolution of blood pressure and heart rate levels between both groups were not observed (Figure 3).
Differences in maternal adverse events were not observed between groups (Table VI). Only one patient in $\mathrm{G}_{12}(3.3 \%)$ developed nausea and one patient in $\mathrm{G}_{8}$ (3.3\%) developed dyspnea. Patients did not complain of pain, discomfort, or developed vomiting until the end of the procedure. Anesthetic supplementation was not necessary.

Data on newborns were homogenous in both groups (Table VII). Only one newborn in $\mathrm{G}_{12}$ had an Apgar of three in the first minute. All other newborns had an Apgar of seven in the first minute. On the fifth minute, they all scored more than seven.

Blood gases and lactate levels in the umbilical vein and artery were measured at a mean time of 20.29 minutes and 19.71 minutes in $G_{12}$ and $G_{8}$, respectively, after blood collection. The greatest time interval between blood collection and exams was 42 and 43 minutes in $\mathrm{G}_{12}$ and $\mathrm{G}_{8}$, respectively.

Table III - Anesthetic-Surgical Times

\begin{tabular}{llll}
\hline & $\mathbf{G}_{12}$ & $\mathbf{G}_{\mathbf{8}}$ & $\mathbf{p}$ \\
\hline Anesthesia-delivery (minutes) & $23.3 \pm 5.6$ & $18.6 \pm 4.7$ & $0.0009^{*}$ \\
Uterotomy-delivery (seconds) & $75 \pm 53.6$ & $73.9 \pm 60.8$ & 0.695 \\
Anesthesia-end of surgery (minutes) & $72.44 \pm 15.70$ & $67.33 \pm 12.74$ & 0.17 \\
\hline
\end{tabular}

Results presented as mean \pm standard deviation.

*Significant statistics: $p<0.05$.

Table IV - Consumption of Vasopressors and Hemodynamic Variables

\begin{tabular}{|c|c|c|c|}
\hline & $\mathrm{G}_{12}$ & $\mathrm{G}_{8}$ & $\mathrm{p}$ \\
\hline Total mass of phenylephrine administered $(\mu \mathrm{g})$ & $1,024.3 \pm 277.4$ & $794.4 \pm 281.1$ & $0.0023^{*}$ \\
\hline Mass of phenylephrine /infusion time $\left(\mu \mathrm{g} \cdot \mathrm{min}^{-1}\right)$ & $44.06 \pm 6.63$ & $44.18 \pm 13.97$ & 0.957 \\
\hline Incidence of hypotension** & $7(23 \%)$ & $2(6.6 \%)$ & 0.145 \\
\hline Bradycardia** $^{\star *}$ & $4(13.4 \%)$ & $5(16.7 \%)$ & 0.735 \\
\hline Administration of atropine ${ }^{* *}$ & $0(0 \%)$ & $0(0 \%)$ & 1 \\
\hline
\end{tabular}

Results presented as mean \pm standard deviation for phenylephrine consumption. Other data are $\left.{ }^{* \star}{ }^{*}\right)$ presented as $n$ and $(\%)$. ${ }^{*}$ Significant statistics: $p<0.05$.

Table V - Maximum and Minimum Blood Pressure and Heart Rate in G12 e G8

\begin{tabular}{llll}
\hline & $\mathrm{G}_{12}$ & $\mathrm{G}_{8}$ & $\mathrm{p}$ \\
\hline $\begin{array}{l}\text { Systolic blood pressure } \\
\text { Maximum (mmHg) }\end{array}$ & $140.4 \pm 10.8(122-167)$ & $137.2 \pm 11.0(115-155)$ & 0.25 \\
$\quad$ Minimum (mmHg) & $108.5 \pm 12.0(77-140)$ & $112.7 \pm 10.3(91-134)$ & 0.15 \\
Heart rate & & & 0.88 \\
$\quad$ Maximum (bpm) & $90.1 \pm 11.8(66-115)$ & $89.6 \pm 13.1(66-112)$ & 0.98 \\
Minimum (bpm) & $60.7 \pm 7.9(48-75)$ & $60.8 \pm 10.2(46-89)$ & \\
\hline
\end{tabular}

Results presented as mean \pm standard deviation (maximum and minimum).

Table VI - Adverse Maternal Events

\begin{tabular}{llll}
\hline & $\mathrm{G}_{12}$ & $\mathrm{G}_{8}$ & $\mathrm{P}$ \\
\hline Nausea & $1(3.3 \%)$ & $0(0 \%)$ & 1 \\
Vomiting & $0(0 \%)$ & $0(0 \%)$ & 1 \\
Pain & $0(0 \%)$ & $0(0 \%)$ & 1 \\
Dyspnea & $0(0 \%)$ & $1(3.3 \%)$ & 1 \\
Tremors & $4(13.3 \%)$ & $6(20 \%)$ & 0.729 \\
\hline
\end{tabular}

Results presented as number of episodes (percentage). 
Table VII - Newborn Characteristics

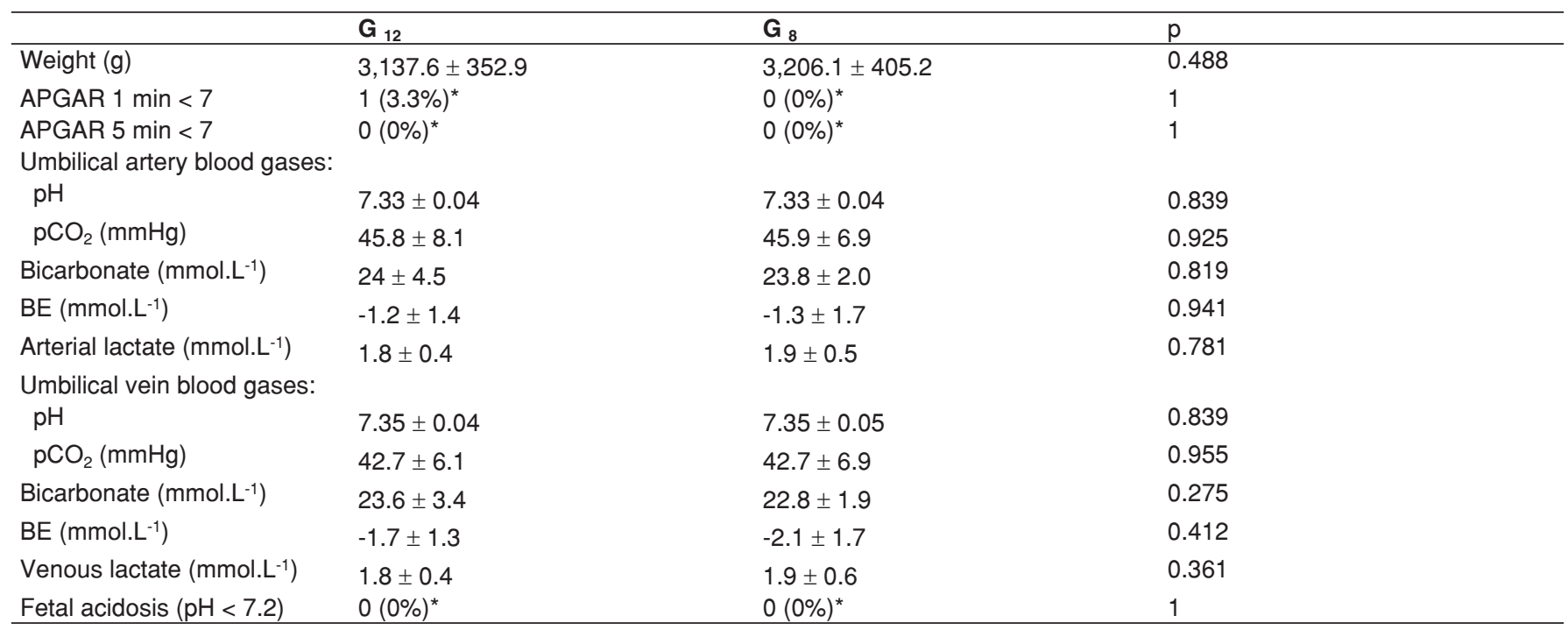

${ }^{*}$ Results are presented as number and percentage.

\section{DISCUSSION}

This study questions the benefits of reducing the mass of local anesthetic in spinal anesthesia for elective cesarean sections with prophylactic continuous infusion of phenylephrine for maternal and fetal results.

In clinical practice the choice of the mass of local anesthetic administered is made intuitively according to the agility and experience of surgical teams, considering the greater dispersion of anesthetics in gravidas. The choice of higher and lower anesthetic mass, $12 \mathrm{mg}$ or $8 \mathrm{mg}$, was made for surgical teams knowingly with greater and lower surgical times, respectively. The homogeneity of sample characteristics and study groups decreased the bias due to non-randomized group selection.

The choice of $12 \mathrm{mg}$ of hyperbaric bupivacaine is justified, as it is a dose traditionally used in spinal anesthesia for cesarean sections in clinical practice. On the other hand the dose of $8 \mathrm{mg}$ associated with liposoluble opioids represents a $33.33 \%$ reduction in total mass of bupivacaine, and it can be safely used in spinal anesthesia for cesarean sections ${ }^{12,20}$. A recent study reported that doses from $5 \mathrm{mg}$ to $7 \mathrm{mg}$ of hyperbaric bupivacaine associated with opioids can only be used in combined anesthesia, and the presence of epidural catheter for analgesic supplementation is mandatory. The dose of $8 \mathrm{mg}$ used in the present study is above the minimal limit recommended by the authors, and it can be safely administered in single-puncture spinal anesthesia without the need for combined anesthesia. Only one study, by Bryson et al. ${ }^{22}$, demonstrated the safety of using $4.5 \mathrm{mg}$ of isobaric bupivacaine associated with $50 \mu \mathrm{g}$ of fentanyl and $200 \mu \mathrm{g}$ of morphine in spinal anesthesia for cesarean sections. Therefore, the repetition of this data is necessary to change conducts in clinical practice.

The association of liposoluble opioids and local anesthetic in spinal anesthesia for cesarean sections promotes better quality of the anesthetic blockade with effective reduction in the visceral component of pain during cesarean sections ${ }^{23}$. Subarachnoid doses greater than $5 \mu \mathrm{g}$ of sufentanil are associated with improvement in the quality of the anesthetic blockade, but they increase significantly the incidence of side effects, such as pruritus ${ }^{23,24}$. The association of sufentanil and local anesthetic for spinal anesthesia reduces the latency of the anesthetic blockade, improves the intraoperative quality, and provides analgesia in the immediate postoperative period, lasting approximately 6 hours ${ }^{25}$.

Morphine was associated with the anesthetic solution to provide longer lasting analgesia in the immediate postoperative period. Because morphine is a hydrosoluble opioid, its onset of action is delayed and longer lasting when compared to liposoluble opioids ${ }^{10}$. A standardized dose of $100 \mu \mathrm{g}$ of morphine was used because studies have reported that higher doses do not add benefits and they are associated with greater incidence of pruritus ${ }^{26-28 .}$

One of the main changes on the concepts related to the administration of spinal anesthesia for cesarean section is related to the prevention of hypotension after spinal anesthe-

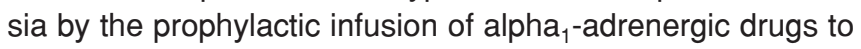
achieve minimal reductions in blood pressure. Prophylactic continuous administration of phenylephrine reduces the incidence of maternal nausea and vomiting resulting in greater umbilical artery and vein $\mathrm{pH}^{17}$. In the present study, it was decided to use prophylactic continuous infusion of phenylephrine for hemodynamic control aiming at minimal reduction in blood pressure.

Several reports in the literature have shown the benefits of reducing the mass of local anesthetic in spinal anesthesia for cesarean section, with a reduction in the incidence of maternal hypotension, nausea, and vomiting, besides reduced consumption of vasopressors 12,13,16,22,29. However, in those studies vasopressors were administered whenever the blood pressure showed a reduction equal or greater than $30 \%$ in baseline systolic blood pressure or a systolic blood pressure 
below $90 \mathrm{mmHg}$ after spinal anesthesia. But this strategy no longer represents the gold standard in spinal anesthesia for cesarean section.

On the other hand, studies that used the strategy of prophylactic phenylephrine for pressure control are rare in this context of reducing the mass of local anesthetic as their focus was basically on different modes of administration of phenylephrine. Thus, a fixed dose of local anesthetic was used varying the mode of administration of this vasopressor ${ }^{19}$.

In the present study, sensorial blockade levels were measured 5 and 10 minutes after the subarachnoid injection, suggesting similar dispersion of the anesthetic in the study groups. After 10 minutes, sensorial level reached $T_{6}$ in both groups. This level of blockade is considered safe for the beginning of a surgery ${ }^{30}$.

Sympathetic blockade levels can reach up to four dermatomes above the sensorial blockade ${ }^{31}$. The blockade level 10 minutes ( $T_{6}$ in both groups) after spinal anesthesia blocks practically all sympathetic chain. Dispersion of local anesthetics in the subarachnoid space can extend for up to 20 to 25 minutes after subarachnoid injection ${ }^{31}$. Considering the level of blockade at 10 minutes, the additional dispersion of the local anesthetic probably did not influence the incidence of hypotension and consumption of vasopressors.

Total phenylephrine consumption was greater in $\mathrm{G}_{12}$ than in $\mathrm{G}_{8}$. This difference can be explained by the non-randomization of the study groups and greater local anesthetic mass administered by those surgical teams with longer surgical times. The group of $12 \mathrm{mg}$ hyperbaric bupivacaine showed greater time interval between the subarachnoid administration and fetal extraction and, therefore, greater infusion time and greater total consumption of phenylephrine.

The difference in total phenylephrine consumption cannot be attributed to differences in sensorial blockade level due to the homogeneity of anesthetic blockade levels, which were not different between groups.

Total phenylephrine consumption was $1,024 \mu \mathrm{g}$ in $\mathrm{G}_{12}$, and it was demonstrated to be safe for use in spinal anesthesia for cesarean section. The administration of a total mass of phenylephrine up to $1,500 \mu \mathrm{g}$ has been described in literature as not causing maternal and fetal adverse events ${ }^{17}$. Currently, phenylephrine is the first-line drug for prevention of hypotension after spinal anesthesia ${ }^{32}$.

Variation in the mass of the local anesthetic administered did not have impact in the reduction or increase in vasopressor consumption by unit of time. Adjusting the total phenylephrine consumption to the infusion time $\left(\mu \mathrm{g} \cdot \mathrm{min}^{-1}\right)$, differences were not observed between groups, confirming that the greatest total consumption in $\mathrm{G}_{12}$ was due to the longer infusion time. However, studies published have demonstrated a reduction in vasopressor consumption with the reduction in local anesthetic mass ${ }^{12-16}$. The difference regarding the results in our study can be explained by the fact that the authors adopted a therapeutic strategy of vasopressor administration.

Several publications used a fixed dose of local anesthetic and evaluated different doses and administration routes of phenylephrine isolatedly or combined with other vasopres- sors when analyzing its effects and adverse events 17,19,33. Recently, the effects of prophylactic phenylephrine infusion were analyzed in 80 patients who underwent spinal anesthesia for cesarean section with $10 \mathrm{mg}$ or $7 \mathrm{mg}$ of isobaric bupivacaine associated with $4 \mathrm{mcg}$ of sufentanil ${ }^{34}$. The rate of phenylephrine infusion was lower than the rate of infusion in the present study. The authors observed that smaller hemodynamic changes are associated with the administration of low doses of local anesthetic combined with continuous infusion of phenylephrine.

The incidence of hypotension observed with the protocol of prophylactic phenylephrine administration is in agreement with the study of $\mathrm{Ngan}$ Kee et al. ${ }^{17}$, who observed a $16 \%$ incidence of hypotension, in which they defined hypotension as a fall greater than $20 \%$ in baseline systolic blood pressure after the subarachnoid administration of $10 \mathrm{mg}$ of bupivacaine.

Although we observed low incidence of hypotension in $\mathrm{G}_{8}$, a study published by the same group of Ngan Kee et al. ${ }^{19}$ observed a smaller incidence of hypotension, $1.2 \%$. This difference can be explained by the infusion of a large volume of crystalloid (2,000 mL of Ringer's lactate) before the administration of spinal anesthesia, contrary to the maximum volume of $1,000 \mathrm{~mL}$ of Ringer's lactate administered up to fetal extraction in our study.

The main maternal adverse effects caused by the continuous infusion of phenylephrine were hypertension and bradycardia. The mean incidence of hypertension in both groups was lower than the results reported in literature, whose incidence can reach up to $47 \%$ without negative maternal and fetal repercussions ${ }^{19}$.

In literature the incidence of bradycardia with phenylephrine infusion reaches up to $5 \%{ }^{15,35}$, which might require the administration of atropine. Bradycardia may result from phenylephrine-induced increase in peripheral vascular resistance that leads to an increase in left ventricular afterload and reduction in heart rate ${ }^{36}$. In the present study a greater incidence of bradycardia was observed in the $8 \mathrm{mg}(16.7 \%)$ group. Ngan Kee et al. ${ }^{19}$ reported a $24.8 \%$ incidence of bradycardia with a $100 \mu \mathrm{g} \cdot \mathrm{min}^{-1}$ infusion of phenylephrine.

Our results show that episodes of bradycardia were not followed by hemodynamic repercussions (hypotension), and they did not require the administration of atropine, only interruption of the infusion of vasopressor. These data are also in agreement with the literature 15,19,35. Other cardiac arrhythmias such as ventricular bigeminism were not observed ${ }^{37}$.

The incidence of maternal adverse events was minimal; only $1 / 30(3.3 \%)$ had an episode of nausea in the group of greater mass of local anesthetic. This episode of nausea was observed along with an episode of hypotension with a reduction in systolic blood pressure from $115 \mathrm{mmHg}$ to $90 \mathrm{mmHg}$. The incidence of nausea recorded in both groups was smaller than that reported in literature whose incidence can reach up to $16 \%{ }^{17}$.

The low incidence of nausea and vomiting observed is secondary to the strict blood pressure control with liposoluble opioids added to the spinal anesthesia solution. Approximately $80 \%$ of episodes of nausea and vomiting are secondary 
to hypotension. Other causes of intraoperative nausea and vomiting include surgical stimuli, such as peritoneal and intraabdominal organ manipulation and traction. Addition of subarachnoid analgesic to the local anesthetic solution improves the quality of anesthetic blockade and reduces the incidence of intraoperative nausea and vomiting ${ }^{23}$. Non-prophylactic pressure control strategies after spinal anesthesia have higher incidence of maternal adverse events, such as nausea and vomiting, which can afflict up to $40 \%$ of patients ${ }^{12,13,36,38}$.

In this study patients did not complain of pain and/or discomfort during surgical procedure, and they did not require anesthetic supplementation which demonstrates the safe use of $8 \mathrm{mg}$ hyperbaric bupivacaine in single-puncture spinal anesthesia associated with $5 \mu \mathrm{g}$ sufentanil and $100 \mu \mathrm{g}$ morphine in cesarean sections with a mean duration of 67 minutes. Masses of hyperbaric bupivacaine of $5 \mathrm{mg}$ and $7 \mathrm{mg}$ can be administered in cesarean sections with 50- and 70-minute duration ${ }^{21}$. However, for such doses combined anesthesia is recommended ${ }^{21}$.

Fetal results did not show a significant difference when the mass was reduced from $12 \mathrm{mg}$ to $8 \mathrm{mg}$. Only one newborn in the 12-mg group had an Apgar of three in the first minute, On this cesarean section, the uterotomy-delivery time was 5 minutes and 33 seconds, resulting in a greater period of ischemia, justifying the low initial score; $\mathrm{pH}$ of the umbilical artery and vein in this fetus was higher than 7.20, and the Apgar score on the fifth minute was 9 without evidence of fetal suffering.

Mean $\mathrm{pH}$ in the umbilical artery and vein were 7.33 and 7.35 in both groups. These levels are higher than those in other studies ${ }^{17}$, and they are in disagreement with the metaanalysis of Reynolds and Seed ${ }^{39}$, for whom spinal anesthesia for cesarean section would be associated with worsening fetal acid-base status when compared to epidural and general anesthesia. The authors evaluated 27 studies including studies from the decade of 1960 , and concluded that the $\mathrm{pH}$ of patient undergoing spinal anesthesia was lower than that of patients undergoing general and epidural anesthesia, and this difference was 0.015 . The concepts and strategies of spinal anesthesia in the decade of 1960 were different from current ones, and the administration of ephedrine could be responsible for this difference in results. After crossing the placental barrier, ephedrine would increase fetal metabolisms and release catecholamines ${ }^{9,40-42}$. A large placental transference of ephedrine is observed when compared to phenylephrine resulting in fetal repercussions with a significant increase in circulating catecholamines ${ }^{43}$. The safety of using phenylephrine in spinal anesthesia for cesarean section was observed, and these results have been confirmed by several clinical and experimental studies ${ }^{44,47}$. We demonstrated that the use of alpha ${ }_{1}$-adrenergic drugs is safe and effective, and the umbilical artery and vein pH was 7.33 and 7.35 in $G_{12}$ and $G_{8}$, respectively. This $\mathrm{pH}$ revealed good delivery conditions related with spinal anesthesia, as well as the safety of administering phenylephrine on fetal acid-base status ${ }^{32}$.

Umbilical artery and vein blood were collected by the double-clamping technique with a heparinized syringe, and all samples were analyzed within 60 minutes after collection. The American College of Gynecology and Obstetrics recommends analysis of the samples within 60 minutes of collection in a heparinized syringe ${ }^{48}$. Studies on the effects of time on the results of blood gases in the umbilical artery and vein observed that 60 minutes after the collection $\mathrm{pH}$ levels did not change ${ }^{49}$; however, levels of $\mathrm{pCO}_{2}$ were significantly reduced, while $\mathrm{pO}_{2}$ increased. The study questions the efficacy of reducing the mass of local anesthetic on maternal and fetal results in patients undergoing spinal anesthesia for elective cesarean section with strict blood pressure control with infusion of phenylephrine. Prevention of hypotension by using a prophylactic strategy, such as infusion of vasopressors, substitutes the beneficial effects of reducing the mass of local anesthetics on maternal and fetal results.

However, this study did not assess occasional differences between the maternal results that could be observed after fetal extraction, such as the time of regression of the motor blockade, use of uterotonic drugs, and postoperative analgesia; these data would also be related to maternal satisfaction ${ }^{22,50}$.

We conclude that, in patients undergoing spinal anesthesia for elective cesarean section with strict blood pressure control with phenylephrine, the variation in the mass of hyperbaric bupivacaine from $12 \mathrm{mg}$ to $8 \mathrm{mg}$ is not associated with differences in the incidence of adverse maternal events, quality of anesthetic blockade until the end of the procedure, and conditions of fetal delivery. 
11. Lew $E$, Yeo SW, Thomas E - Combined spinal-epidural anesthesia using epidural volume extension leads to faster motor recovery after elective cesarean delivery: a prospective, randomized, double-blind study. Anesth Analg, 2004;98:810-814.

12. Ben-David B, Miller G, Gavriel R et al. - Low-dose bupivacaine-fentanyl spinal anesthesia for cesarean delivery. Reg Anesth Pain Med, 2000;25:235-239.

13. Fan SZ, Susetio L, Wang YP et al. - Low dose of intrathecal hyperbaric bupivacaine combined with epidural lidocaine for cesarean section--a balance block technique. Anesth Analg, 1994;78:474-477.

14. Vercauteren MP, Coppejans HC, Hoffmann VL et al. - Small-dose hyperbaric versus plain bupivacaine during spinal anesthesia for cesarean section. Anesth Analg, 1998;86:989-993.

15. Vercauteren MP, Coppejans HC, Hoffmann VH et al. - Prevention of hypotension by a single 5-mg dose of ephedrine during small-dose spinal anesthesia in prehydrated cesarean delivery patients. Anesth Analg, 2000;90:324-327.

16. Choi DH, Ahn HJ, Kim JA - Combined low-dose spinal-epidural anesthesia versus single-shot spinal anesthesia for elective cesarean delivery. Int J Obstet Anesth, 2006;15:13-17.

17. Ngan Kee WD, Khaw KS, Ng FF - Compariso of phenylephrine infusion regimens for maintaining maternal blood pressure during spinal anaesthesia for Caesarean section. Br J Anaesth, 2004;92:469-474.

18. Ngan Kee WD, Khaw KS - Vasopressors in obstetrics: what should we be using? Curr Opin Anaesthesiol, 2006;19:238-243.

19. Ngan Kee WD, Khaw KS, Ng FF - Prevention of hypotension during spinal anesthesia for cesarean delivery: an effective technique using combination phenylephrine infusion and crystalloid cohydration. Anesthesiology, 2005;103:744-750.

20. Dyer RA, Joubert IA - Low-dose spinal anaesthesia for caesarean section. Curr Opin Anaesthesiol, 2004;17:301-308.

21. Roofthooft E, Van de Velde M - Low-dose spinal anaesthesia for Caesarean section to prevent spinal-induced hypotension. Curr Opin Anaesthesiol, 2008;21:259-262.

22. Bryson GL, Macneil R, Jeyaraj LM et al. - Small dose spinal bupivacaine for Cesarean delivery does not reduce hypotension but accelerates motor recovery. Can J Anaesth, 2007;54:531-537.

23. Balki M, Carvalho JC - Intraoperative nausea and vomiting during cesarean section under regional anesthesia. Int J Obstet Anesth, 2005; 14:230-241.

\section{REFERÊNCIAS / REFERENCES}

01. Jenkins JG, Khan MM - Anaesthesia for caesarean section: a survey in a UK region from 1992 to 2002. Anaesthesia, 2003;58:1114-1118.

02. Stamer UM, Wiese $R$, Stuber $F$ et al. - Change in anaesthetic practice for Caesarean section in Germany. Acta Anaesthesiol Scand, 2005;49:170-176.

03. Ng K, Parsons J, Cyna AM et al. - Spinal versus epidural anaesthesia for caesarean section. Cochrane Database Syst Rev, 2004(2):CD003765.

04. Hawkins $\mathrm{JL}$, Gibbs CP, Orleans $M$ et al. - Obstetric anesthesia work force survey, 1981 versus 1992. Anesthesiology, 1997;87:135-143.

05. Bloom SL, Spong CY, Weiner SJ et al. - Complications of anesthesia for cesarean delivery. Obstet Gynecol., 2005;106:281-287.

06. Khaw KS, Ngan Kee WD, Lee SW - Hypotension during spinal anaesthesia for caesarean section: implications, detection, prevention and treatment. Fetal Maternal Med Rev, 2006;17:157-183

07. Kinsella SM, Lohmann G - Supine hypotensive syndrome. Obstet Gynecol, 1994;83(5 Pt 1):774-788.

08. Cyna AM, Andrew M, Emmett RS et al. - Techniques for preventing hypotension during spinal anaesthesia for caesarean section. Cochrane Database Syst Rev, 2006(4):CD002251.

09. Ngan Kee WD, Khaw KS, Lee BB et al. - A dose-response study of prophylactic intravenous ephedrine for the prevention of hypotension during spinal anesthesia for cesarean delivery. Anesth Analg, 2000;90:1390-1395.

10. Rathmell JP, Lair TR, Nauman B - The role of intrathecal drugs in the treatment of acute pain. Anesth Analg, 2005;101(5 Suppl):S30-43.

24. Braga Ade F, Braga FS, Poterio GM et al. - Sufentanil added to hyperbaric bupivacaine for subarachnoid block in Caesarean section. Eur J Anaesthesiol, 2003;20:631-635

25. Gordon K, Lima RT, Yamashita AM - Anestesia subaracnoidea para cesariana com bupivacaína hiperbárica a 0,5\% associada a sufentanil e fentanil. Rev Bras Anestesiol, 1997;47:211-218.

26. Palmer CM, Emerson S, Volgoropolous D et al. - Dose-response relationship of intrathecal morphine for postcesarean analgesia. Anesthesiology, 1999;90:437-444.

27. Dahl JB, Jeppesen IS, Jorgensen $\mathrm{H}$ et al. - Intraoperative and postoperative analgesic efficacy and adverse effects of intrathecal opioids in patients undergoing cesarean section with spinal anesthesia: a qualitative and quantitative systematic review of randomized controlled trials. Anesthesiology, 1999;91:1919-1927.

28. Sarvela J, Halonen $\mathrm{P}$, Soikkeli A et al. - A double-blinded, randomized comparison of intrathecal and epidural morphine for elective cesarean delivery. Anesth Analg, 2002;95:436-440.

29. Chen $X Z$, Chen $H$, Lou AF et al. - Dose-response study of spinal hyperbaric ropivacaine for cesarean section. J Zhejiang Univ Sci B, 2006;7:992-997.

30. Yentis SM - Height of confusion: assessing regional blocks before caesarean section. Int J Obstet Anesth, 2006;15:2-6.

31. Hocking G, Wildsmith JA - Intrathecal drug spread. $\mathrm{Br} J$ Anaesth, 2004;93:568-578

32. Ngan Kee WD - Prevention of maternal hypotension after regional anaesthesia for caesarean section. Curr Opin Anaesthesiol, 2010;23:304309.

33. Ngan Kee WD, Khaw KS - Low-dose spinal anesthesia with low-dose phenylephrine infusions for cesarean delivery: better but not necessarily best. Anesthesiology, 2009;111:210-211. 
34. Langesaeter E, Rosseland LA, Stubhaug A - Continuous invasive blood pressure and cardiac output monitoring during cesarean delivery: a randomized, double-blind comparison of low-dose versus high-dose spinal anesthesia with intravenous phenylephrine or placebo infusion. Anesthesiology, 2008;109:856-863.

35. Mercier FJ, Bonnet MP, De la Dorie A et al. - Rachianesthésie pour césarienne: remplissage, vasopresseurs et hypotension. Ann Fr Anesth Reanim. 2007;26:688-693.

36. Macarthur A, Riley ET - Obstetric anesthesia controversies: vasopressor choice for postspinal hypotension during cesarean delivery. Int Anesthesiol Clin, 2007:45:115-132.

37. Lai FM, Jenkins JG - Ventricular bigeminy during phenylephrine infusion used to maintain normotension during caesarean section under spinal anaesthesia. Int J Obstet Anesth, 2007;16:288-290.

38. Ngan Kee WD, Khaw KS, Ng FF et al. - Prophylactic phenylephrine infusion for preventing hypotension during spinal anesthesia for cesarean delivery. Anesth Analg, 2004;98:815-821.

39. Reynolds F, Seed PT - Anaesthesia for Caesarean section and neonatal acid-base status: a meta-analysis. Anaesthesia, 2005;60:636-653.

40. Cooper DW, Carpenter M, Mowbray $P$ et al. - Fetal and maternal effects of phenylephrine and ephedrine during spinal anesthesia for cesarean delivery. Anesthesiology, 2002;97:1582-1590.

41. Ramin SM, Ramin KD, Cox K et al. - Comparison of prophylactic angiotensin II versus ephedrine infusion for prevention of maternal hypotension during spinal anesthesia. Am J Obstet Gynecol, 1994;171:734739.

42. Ngan Kee WD, Lee A, Khaw KS et al. - A randomized double-blinded comparison of phenylephrine and ephedrine infusion combinations to maintain blood pressure during spinal anesthesia for cesarean delivery: the effects on fetal acid-base status and hemodynamic control. Anesth Analg, 2008;107:1295-1302.

43. Ngan Kee WD, Khaw KS, Tan PE et al. - Placental transfer and fetal metabolic effects of phenylephrine and ephedrine during spinal anesthesia for cesarean delivery. Anesthesiology, 2009;111:506-512.

44. Lee A, Ngan Kee WD, Gin T - A quantitative, systematic review of randomized controlled trials of ephedrine versus phenylephrine for the management of hypotension during spinal anesthesia for cesarean delivery. Anesth Analg, 2002;94:920-926.

45. Erkinaro T, Kavasmaa T, Pakkila $M$ et al. - Ephedrine and phenylephrine for the treatment of maternal hypotension in a chronic sheep model of increased placental vascular resistance. Br J Anaesth, 2006;96:231237.

46. Magness RR, Rosenfeld CR - Systemic and uterine responses to alpha-adrenergic stimulation in pregnant and nonpregnant ewes. Am J Obstet Gynecol, 1986;155:897-904

47. Reidy J, Douglas J - Vasopressors in obstetrics. Anesthesiol Clin, 2008;26:75-88.

48. ACOG Committee on Obstetric Practice - ACOG Committee Opinion No. 348, November 2006: Umbilical cord blood gas and acid-base analysis. Obstet Gynecol, 2006;108:1319-1322.

49. Valenzuela P, Guijarro R - The effects of time on $\mathrm{pH}$ and gas values in the blood contained in the umbilical cord. Acta Obstet Gynecol Scand, 2006;85:1307-1309.

50. Carvalho B, Cohen SE, Lipman SS et al. - Patient preferences for anesthesia outcomes associated with cesarean delivery. Anesth Analg, 2005; 101:1182-1187.
Resumen: Souza VP, Amaral JLG, Tardelli MA, Yamashita AM Efectos de la Infusión Continua Profiláctica de Fenilefrina sobre la Estrategia de Reducción de la Masa de Anestésico Local en Pacientes Sometidas a la Raquianestesia para Cesárea.

Justificativa y objetivos: La reducción de la masa del anestésico local minimiza los efectos de la hipotensión arterial postraquianestesia para cesárea, y reduce la incidencia de eventos adversos maternos preservando el bienestar fetal, pero puede conllevar a una anestesia insuficiente. La hipotensión asociada a las mayores masas de anestésico subaracnóideo puede ser controlada con una infusión continua profiláctica de fenilefrina. Fueron evaluados los efectos de la infusión continua profiláctica de fenilefrina para el control presórico sobre los resultados maternos y conceptuales, en cesáreas con diferentes dosis de bupivacaína hiperbárica en la raquianestesia.

Método: Se realizó un ensayo clínico prospectivo, no aleatorio con 60 embarazadas a término, admitidas para la cesárea electiva. Las pacientes fueron ubicadas en dos grupos, en dependencia de la dosis de bupivacaína hiperbárica administrada en la raquianestesia, 12 u $8 \mathrm{mg}$, añadida de $5 \mu \mathrm{g}$ de sufentanil y $100 \mu \mathrm{g}$ de morfina. Se realizó la hidratación con $10 \mathrm{~mL} . \mathrm{kg}^{-1}$ de solución de Ringer con lactato antes del bloqueo. Inmediatamente se inició la infusión continua de $100 \mu \mathrm{g}$. $\mathrm{min}^{-1}$ de fenilefrina, manteniendo la presión arterial en los valores basales. Fueron evaluados: nivel de bloqueo anestésico, consumo de vasopresores, incidencia de eventos adversos maternos y condiciones del recién nacido.

Resultados: Los datos maternos fueron similares entre los grupos en cuanto al nivel de bloqueo anestésico, consumo de fenilefrina por tiempo, incidencias de hipotensión, bradicardia, náuseas, vómitos, disnea, dolor y temblores. Los datos conceptuales arrojaron una similitud entre los grupos en cuanto a la gasometría y a la dosificación de lactato en los vasos umbilicales. Todos los recién nacidos presentaron un $\mathrm{pH}>7,2$.

Conclusiones: Manteniendo la presión arterial con infusión profiláctica continua de fenilefrina, la incidencia de eventos adversos maternos y las condiciones de nacimiento conceptuales no son diferentes cuando la raquianestesia se hace con $12 \mathrm{mg}$ u $8 \mathrm{mg}$ de bupivacaína hiperbárica.

Descriptores: ANESTESIA: Obstétrica; ANESTÉSICOS: Local, bupivacaína; CIRUGÍA: Cesárea; COMPLICACIONES; FÁRMACOS: fenilefrina; TÉCNICAS ANESTÉSICAS: Regional, subaracnoidea. 